the college placed sixth out of the 28 participating colleges. Chapter Treasurer Cegeon Chan placed first for the college. From this past forecast period, there were 11 people that did not qualify. Forms were made available at the end of the meeting for any member who wanted to drop out of the contest. Arnott announced that preparations for the panel discussion at the Storm Conference was going well, as three out of the five slots were filled.

Freedman and Chapter Secretary Tracy McCormick said they were working on listing all of the people that had registered for the Storm Conference in a spreadsheet. McCormick said she was also working on putting together the Storm Conference booklet, which included all of the oral presentation abstracts for the conference. Additionally, she was in the process of getting the science fair underway, and had already been in touch with three local schools that would like to participate. She asked if any member wanted to be a judge or to give meteorology lab and television station tours.

Chan announced that the budgeting process was underway. He said approximately $25 \%$ of the money cut at the house meeting was from the AMS budget. He invited members to come and support their club at these meetings. Chan thanked everyone who helped out at the Winter Ball, noting there was a record-breaking turnout this year. He said there would be another car-wash fund-raiser this spring, and club members were invited to help plan a nature walk for children to be held on Spring Day (28 April 2001).

McCormick announced that Dr. Atkins's wife went into labor that evening and that there would be another meeting after Winter Break for student members to sign a card and see the gift that the chapter would be giving to Dr. Atkins and his wife.

Two raffle prizes were given out at the end of the meeting. Raffle winners were Mike DiVirgilio and Tony Mandella.-Tracy L. McCormick.

\section{Central Illinois}

The most recent meeting was held on 5 December 2000, at Maverick Steakhouse in Clinton, Illinois. A short business meeting was followed by a speaker, Charles Schweighauser, professor of astronomy and physics at the University of Illinois at Springfield. His program was titled "Stars and Galaxies." He spoke on the formation, structure, and end of stars, and then focused on the Milky Way galaxy. Schweighauser's presentation included many slides from the Hubble Space Telescope.

The next meeting was tentatively scheduled for 1 March 2001 in Lincoln, Illinois. The speaker was yet to be named, but the topic was to be severe weather. The chapter also planned to appoint members to the membership, program, and publicity committees and to elect chairpersons as per the bylaws.

Information about future meetings of the chapter can be found online at http://www.crh.noaa.gov/ilx/ ams.htm.-Ed Kieser.

\section{Climate and Skin Cancer}

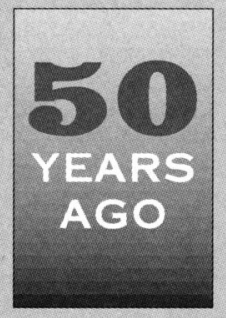

While the United States is within the temperate zone of climate, the size and geographical arrangement of our country give wide climatic variations of insolation, temperature, moisture, wind, altitude, dust, and industrial smoke. ... In general, there is more skin cancer in the southern states than elsewhere, with a maximum incidence in the Southwest and with the best data from Texas. ... This disease is so common in Texas and its neighboring states that the doctors there have always known it ... this area [is] a perfect one for study of this disease because in the Southwest we have long hours of insolation, extensive dry and dusty areas, little industrial "smog," and a population about half of whom engage in some type of outdoor occupation. . . . The sunshine map of the Weather Bureau shows insolation is greatest in the southwestern United States. In general, skin cancer is greatest there also. The area of most sunshine ( 3,800 hours per year) is in our far Southwest, with much of it in Arizona; and, if great exposure to the ultraviolet element of sunshine alone were the cause of skin cancer, then the population of that state should show the greatest incidence. . . . Medical statistics from Arizona record the incidence of skin cancer as not so high. Of the sun-rich states of Arizona, New Mexico, Oklahoma, and Texas, the largest number of skin cancers is recorded from the latter ... this fact [is] a final argument that climate is not the only factor in producing skin cancer.

Bull. Amer. Meteor. Soc., 32, 187. 